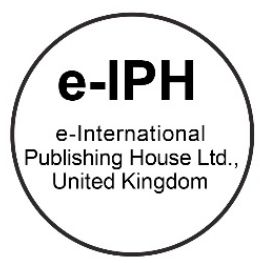

\title{
Spatial Ability Skills: A correlation between Augmented Reality (AR) and conventional way on wayfinding system
}

\author{
Nik Atilla Atasha Shamsuddin *, Sharkawi Che Din \\ Universiti Teknologi MARA, Faculty of Art and Design, 40450 Shah Alam, Malaysia
}

\begin{abstract}
An urban design has become the latest technology in having a quality life for users. With increasing mobility of individuals, there is an increase in demand for a wayfinding system to people who are on the move. However, research regarding the use, evaluation and effect are limited. This research reviews on the conventional and Augmented Reality (AR) based wayfinding approaches and their correlation with the user's spatial ability. A set of questionnaires and research framework with the aid of AR prototype will be used to achieve results.
\end{abstract}

(c) 2016. The Authors. Published for AMER ABRA by e-International Publishing House, Ltd., UK. Peer-review under responsibility of AMER (Association of Malaysian Environment-Behaviour Researchers), ABRA (Association of Behavioural Researchers on Asians) and cE-Bs (Centre for Environment-Behaviour Studies), Faculty of Architecture, Planning \& Surveying, Universiti Teknologi MARA, Malaysia.

Keywords: Wayfinding, Augmented Reality, spatial ability

\section{Introduction}

The ability to recognize visual-spatial world precisely and to achieve transformations on those perceptions are among eight parts that human intelligence embraces is spatial ability (Gardner, 1983). However, this is only one definition of the term "spatial ability". Frequently the terms "spatial ability" and "spatial skills" are used interchangeably irrespective of the distinction made between these terms in educational psychology (Sorby, 1999).

Spatial ability is defined as the natural ability to visualize, and the cognitive processes involved in locating target in space, perceiving distance, and directional relationships, and mentally transforming object with respect to their position or orientation in space before any formal training has occurred. Human naturally are born with this ability. It exists naturally and can be trained to strengthened the skills.

In everyday activities, spatial abilities are applied while finding a way at unfamiliar places. Hence, environmental graphic design (EGD) is playing an important role. One of the many practice areas that fall under the umbrella term of EGD is wayfinding system. Whether we realize it or not, wayfinding system is crucial and useful that will benefit us humans. Wayfinding system is

${ }^{*}$ Corresponding author. Tel.: +6-019-331-4249

E-mail address: nikatillaatasha@gmail.com

(c) 2016. The Authors. Published for AMER ABRA by e-International Publishing House, Ltd., UK. Peer-review under responsibility of AMER (Association of Malaysian Environment-Behaviour Researchers), ABRA (Association of Behavioural Researchers on Asians) and cE-Bs (Centre for EnvironmentBehaviour Studies), Faculty of Architecture, Planning \& Surveying, Universiti Teknologi MARA, Malaysia. DOl: https://doi.org/10.21834/e-bpj.v1i2.279 
the tools that help direct a person from one point to another. Therefore, it is a part of a larger and more holistic design theory that involves creating an atmosphere through the use of graphic design fundamentals. Wayfinding system exists to create an "experience" to users. Consequently, it is crucial to have an organized and proper system, for a greater positive experience to the users if it is interesting and functional.

According to Prall Derek (2014), in his article, it was mentioned that a wayfinding expert and president of Studio L'Image, Sue Labouvie, stated that wayfinding is about an information content and the analysis of the space or place that has been simplified, when one tries to move people through by coming up with a strategy to overcome complex device into a simple and comprehensible to the user. While EGD can be applied to private spaces and marketing, for instance, a shopping complex, wayfinding is exceptionally important in large, public spaces like urban areas such as housing estates, commercial buildings, roads, bridges and railways. Furthermore, in developing an effective wayfinding, one must consider the content that has to be readable and precise so that users will reach to the desired destination or places of interest safely and without difficulties.

Visitors come to a certain place with a broad range of motivations and expectations that can and do affect learning (Falk and Dierking, 2002). In fact, in many ways, by the time a visitor arrives at the front door, the nature and quality of the visiting experience have already been determined to a large degree (Falk and Dierking, 2002). Thus, the wayfinding design plays a critical role in visiting experience in outdoor or indoor places of interest, which affects visitors' learning experience directly.

In conjunction with this research, a wayfinding is an area that can be challenging to train without using the real environment. For example, there are particular difficulties in obtaining wayfinding knowledge in virtual environments. Many of these problems are due to limit navigational metaphors in these environments (Stanney and Salvendy, 1995).

Augmentation promises facilitation in enlightening wayfinding performance in numerous situations, where users are unfamiliar with a certain space, and may need external information to achieve an objective. For example, wayfinding is of contemporary interest for military, public safety agencies, travel industry, and the elderly. The availability of prototypical mobile Augmented Reality (AR) systems now can support studies in wayfinding using various AR strategies (Goldiez, Ahmad and Hancock, 2007).

In this study, spatial ability correlates with spatial comprehension, like verbal comprehension, comprises the capacity to perceive, understand, remember, and recall for future use (Darken and Peterson, 2001). This understanding of reading wayfinding needs to sustain a concept of space and the relative locations of objects and places. These items are essential to certain navigation for the use of users.

\subsection{Background of the research}

- Wayfinding

Wayfinding is the cognitive element of navigation. It does not involve a movement of any kind but only the planned and strategic parts that guide movement. It is not merely a planning stage that precedes motion. Wayfinding and motion are intimately knotted together in a complex negotiation that is navigation. The development and use of a cognitive map also referred to as a mental map, is a vital part of wayfinding. Even though it is still poorly understood, a cognitive map is a mental image of an environment. It has been called a "picture in the head" although there is substantial evidence that it is not purely based on imagery but somewhat has a symbolic quality. The representation of spatial knowledge in human memory that establishes a cognitive map will be a significant part of this research (Darken and Peterson, 2001).

\section{- The map usage}

Maps, photographs, videotape, verbal directions, and recently virtual environments are many secondary sources that have been used for spatial knowledge achievement. The most common of these is the map. For any map utilized in any environment, virtual or real, we need to know when the map is used, or more appropriately, what tasks the map is to be used for. The critical issue is whether or not the map is to be used preceding navigation or parallel with navigation. This issue is vital because maps that are used concurrently with navigation comprise the placement of oneself on the map. The first part of any task of this nature is, "Where am I? What direction am I facing?".

A transformation is required from the egocentric point of view to the geocentric viewpoint. If the map is used as a precursor to navigation, it is used only for planning and familiarization. No perspective transformation is required. Planning a journey is one example of such a geocentric navigation task. The planning is done outside of the environment, so there is no perspective transformation needed. However, the problem is more complicated when such a transformation is required, as in using a map during navigation. (Darken and Peterson, 2001). 
- Augmented Reality (AR) based wayfinding

Wayfinding can be defined as spatial problem solving. It is about knowing where a person is in a building or an environment, knowing where a person desired location is, and knowing how to get there from a person present location. It is engaged in the idea of spatial knowledge. It considers the undertaking in question requiring that navigation (physical movement) take place. Passini (1984) has described;

'Spatial orientation and wayfinding ... allow people an idea of surrounding space, of their positions in that space, and they allow purposeful movement within that space.'

It explains that wayfinding leads or aids map reading. We will refer to navigation as a directed movement action and wayfinding as cognitive action connecting route determination. Therefore, augmentations such as direction indicators, maps, and path restriction can all greatly improve both wayfinding performance and overall user satisfaction (Darken, 1996).

\section{- Spatial ability}

Spatial ability is the capacity to understand and recall the spatial relations among objects. This skill can be perceived as a unique type of intelligence distinguishable from other forms of intelligence, such as verbal ability, reasoning ability, and memory skills. Spatial ability is not a monolithic and static trait but made up of numerous sub-skills, which are interrelated to each other and is developed throughout a person's life. Both men and women have assumed that men are somehow better able to solve sodescribed spatial problems than women. This obvious differentiation has been used to explain the differences in the numbers of men versus women in map reading.

\subsection{Statement of the problem}

Although AR technologies have been widely developed and commercialized, research about the use, evaluation and effect has just started (Yovcheva, et al., 2012; Dünser, Grasset, and Billinghurst, 2008; Linaza, et al., 2012; Swan and Gabbard, 2005).

According to Anastassova, et al., (2005), most of the literature in AR has focused on usability issues. They suggested that there is a need for the implementation of user-based analysis regarding the creation of AR apps and the interactive experience they provide (Gabbard and Swan, 2008). The wayfinding process comprises knowing where you are, knowing your destination, following the best route to your destination, recognize your destination upon arrival, and finding your way back out (Carpman and Grant, 1993).

Previous research (Passini, 1992) proved that wayfinding in a complex environment often causes newcomers and occasionally frequent visitors uncertainty and stress, even with the assistance of wayfinding aids. Maps, landmarks and signs on walls are frequently confusing and not presented inappropriate position or logical sequence (Passini, 1992).

\subsection{Research aim}

This research aims to find the correlation between two types of wayfinding systems (conventional and Augmented Reality based) and the requirement of the spatial ability of the users. It also aims to investigate whether Augmented Reality (AR) based wayfinding can overcome the problems facing by the conventional wayfinding.

\subsection{Research objectives}

The research objectives are;

- to critically assess a group of people from a variety of categories (Age, gender, profession, etc.) in using a conventional map reading based wayfinding.

- to critically assess a group of people from a variety of categories (Age, gender, profession, etc.) in using an Augmented Reality (AR) based wayfinding.

- to assess the above respondent's spatial ability.

- to analyze the statistical association between the two types of wayfinding and the requirements of the spatial ability level.

\subsection{Research questions}

The research questions are derived from the above objectives: 
- How the respondent respond towards conventional wayfinding (map reading)?

- How spatial ability help in conventional way of wayfinding

- Is AR required a certain level of spatial ability skills?

- What are the correlations between two types of wayfinding system that is conventional and Augmented Reality (AR) based and with the use of spatial ability skills?

\section{Methodology}

This research is to understand how the target audience embarks on the area of effective wayfinding, either the conventional type or augmented based type wayfinding. Some factors affecting wayfinding behavior among others, the human individual differences and environment factor (Montello, 2007). This study will provide further understandings into the complex relation between environment legibility and human individual differences (such as spatial abilities, sense of direction, and familiarity) on both types of wayfinding systems (conventional and AR based).

\section{- Research design}

A quantitative methodology incorporates with a proposed framework will be applied to obtain data and information. Findings from the framework will show correlational research information to investigate the wayfinding variables that will be implemented to achieve the research objectives. A purposive sampling strategy will be adopted, for example, using a prototype Augmented Reality (AR) based wayfinding to a group of selected user and a pencil-and-paper survey questionnaire will be provided in collecting data.

\section{Significance of the research}

This research will benefit user of a certain place or location in finding their way to their desired destination without hassle. Besides that, it will encourage the owner of the place or location such as theme park owner and local authority to implement or to improve their wayfinding system. As for a developer, this research will give guidance in designing an integrated wayfinding application. Therefore, AR based wayfinding will become a necessary device in wayfinding.

\section{Literature review}

A comparison of literature survey is needed to obtain results and explanation for the research. In one of the literature, conventional (map) and electronic device for wayfinding indicates that they have complementary strengths and weaknesses. Paper maps have no dynamics and lack of interactive properties compared to electronic map devices, it has high potential for the presentation of up-to-date dynamic content, easy to control and reliable (Paelke and Sester, 2010). Table 1 shows the comparison of conventional map and electronic devices.

Table 1. A comparison of conventional map and electronic devices (Paelke and Sester, 2010)

\begin{tabular}{|c|c|c|c|}
\hline & & Paper maps & Hand-held eMaps \\
\hline \multirow{5}{*}{ Features } & Size & Small to large, foldable, flexible & Small, fixed \\
\hline & Power consumption & None & Significant; endurance hours to days \\
\hline & Weight & Low & Wide range; typically several $100 \mathrm{~g}$ \\
\hline & Price & Low & High \\
\hline & Reliability & Very high & Limited \\
\hline \multirow{5}{*}{ Content } & Resolution (spatial) & Very high & Low \\
\hline & Resolution (temporal) & Very limited (static depictions) & Potentially high (animation) \\
\hline & Flexibility of content & No adaptation, difficult update & Easy if supported by software \\
\hline & Content dimensions & Fixed, limited & Flexible, potentially unlimited \\
\hline & Coverage & Fixed & Potentially unlimited \\
\hline
\end{tabular}




$\begin{array}{ll}\text { Level-of-detail } & \text { Fixed, typically high (use specific) } \\ \text { Readability } & \text { Very high } \\ \text { Information access } & \text { Mostly push; serendipitous discovery } \\ & \text { common }\end{array}$

$\begin{array}{lll}\begin{array}{l}\text { Use and } \\ \text { interaction }\end{array} & \text { Use, interaction } & \begin{array}{l}\text { Well known interaction with paper; but } \\ \text { learned } \\ \text { map skills required } \\ \text { High, but no support for visually impaired }\end{array} \\ \begin{array}{ll}\text { Flexibility of use } \\ \text { ladaptation to other uses } \\ \text { Annotation } \\ \text { Query, search }\end{array} & \text { Very easy, common } \\ \text { Integration of GPS } & \begin{array}{l}\text { Simple with pens, post-its etc. } \\ \text { Multi-user interaction }\end{array} & \begin{array}{l}\text { Only pre-designed indices } \\ \text { None }\end{array} \\ & \text { Very easy, common }\end{array}$

\author{
Lower due to display resolution, flexible \\ Lower \\ Mostly pull; often lack of overview for \\ discoveries \\ if not explicitly supported \\ Special mechanisms, devices specific, only \\ tasks \\ supported by the software \\ Lower, but special mechanisms for target \\ groups \\ can be implemented in software \\ Only if supported by the implementation, \\ typically \\ limited \\ Only if supported by the software \\ Full support possible in software \\ Full support possible in software \\ Difficult due to device size
}

\subsection{Spatial orientation and wayfinding}

According to Darken and Peterson (2001), it is necessary to consider the fact that people are accustomed to navigation in physical spaces, whether or not a virtual environment attempts to simulate the real world. Undoubtedly, there are differences between regions of physical space that alter how navigation works, such as navigating in a forest versus navigating in a city, but there are assumptions that can be made based on experience in real environments that are useful in any real space. Darken and Peterson (2001) also mention, although this is not a satisfactory reason to blindly copy the actual world in every way it can, it certainly has to learn everything possible about how people relate to the physical world so that it can understand how to build better virtual environments.

\subsection{Spatial ability and wayfinding}

Although the behavioral, cognitive, and neural processes involved in wayfinding and navigation are typically treated as synonymous in the literature, important distinctions exist among these processes. Wayfinding is, aptly, the behavior of finding one's way from an origin to one or more destinations; in conventional terms, wayfinding relies on an existing understanding of an environment's spatial characteristics. In most other parts of the world, this understanding relies on existing spatial knowledge gathered from prior navigational experience, maps, or verbal descriptions.

\subsection{Environmental cues}

Wayfinding is based on "consistent use and organization of definite sensory cues from the external environment" (Lynch 1960). Wayfinding exhibits both decision-making and decision execution behavior (Passini, 1984). It is well assumed, to generate knowledge about further actions, and people rely on cues that can be retrieved from the environment (Raudal and Worboys, 1999). Cues are objects within or of environments that people engage in generating mental representations.

Environmental cues fall into several familiar types:

- Signs (e.g. directional signs and informational signs) (Weisman, 1981; Passini, 1984);

- Maps (e.g. You-are-here (YAH) maps and layout maps) (Levine Marchon and Hanley, 1984);

- Landmarks, certain objects that are more prominent than others; (Shanon, 1983; Sorrows and Hirtle, 1999; Denis et al., 1999; Allen, 2000; Michon and Denis, 2001);

- Architectural features that are not landmarks (Lynch, 1960); 
- Layout and structure of the environment (Weisman, 1981; Seidel, 1982; O'Neill, 1991);

- Verbal cues (e.g. communication with other people and/or available help centers). (Freundschuh et al., 1990; Allen Miller and Ondracek, 1997; Denis et al., 1999).

Of these, signs provide the most straightforward wayfinding information (direction, location or confirmation of location). Maps have the capacity to offer all possible information to help the way-seeker. However, as every person has a different ability for comprehending information, compounded further by design and alignment matters associated with maps (Levine, 1982; Levine Machon and Hanley, 1984), a map may also delay wayfinding.

Further, people tend to seek landmarks (often 3 Dimensional), to construct mental representations of unaccustomed environments (Shanon, 1983; Michon and Denis, 2001), especially in the circumstances, when the navigated target is near a known landmark.

When a way-seeker fails to either find the necessary cues (Braaksma and Cook, 1980; Dada and Wirasinghe, 1999; on the viewability of cues), or comprehend conveyed information from a cue, the often consequent behavioral response is to seek help, where available, from information desks or others (Freundschuh et al., 1990; Allen, Miller and Ondracek, 1997; Denis et al., 1999).

\subsection{Wayfinding variables}

This graphical construct gives identity to six wayfinding variables, considered at the node, node-pair and route levels (Braaksma and Jordan, 1980; O'Neill, 1991; Denis, Pazzaglia, Cornoldi and Bertolo, 1999; Dada and Wirasinghe 1999; Allen, 2000). The six wayfinding variables are;

- The number of exit paths

- The Confirmation of informational sign in destination

- Spatial viewability

- Imaginary viewability

- Length in distance

- Length of segments

\subsection{Wayfinding in large-scale virtual worlds}

As important as navigation is to human performance in virtual worlds, support for effective navigation is often overlooked in the design process. An experiment intended to show that real-world wayfinding and environmental design principles are effective in designing virtual worlds, which support skilled wayfinding behavior.

The design principles are adapted from both the cognitive psychology literature and urban and architectural design methodologies. There are two categories of design principles; those that guide the organizational structure of the environment, and those that guide the use and presentation of maps. (Darken, 1996).

The study measures subject performance on a complex searching task in some virtual worlds with differing environmental cues. The environments are enormous and consist of open sea, land, and ships, which are used as targets for search tasks. The worlds are augmented with a radial grid, a map, both, or neither. For each trial, the subject's viewpoint position and orientation were sampled approximately once per second. A verbal protocol with accompanying video was used to elicit information about the search strategies employed. A map drawing exercise followed each trial to gain insight into the subject's spatial knowledge (i.e. cognitive map) of the environment. (Darken, 1996).

The results show that subjects in the treatment without any additional cues were often disoriented and had extreme difficulty completing the task. The grid was shown to provide superior directional information, but both treatments using the map were superior overall due to the geocentric perspective provided. Behaviors associated with each treatment indicate that the cues had a strong effect on both search performance and search strategy. The results suggest that users of large-scale virtual worlds require a structure to navigate effectively. Augmentations such as direction indicators, maps, and path restriction can all greatly improve both wayfinding performance and overall user satisfaction (Darken, 1996).

\subsection{Augmented reality}


Augmented reality (AR) involves overlaying the real world with information from computer-generated displays. Current AR technologies support limited mobility, although this is expected to change in the future. This paper presents experimental results of effects of various AR display strategies on human performance in a simulation-based analog of a "search and rescue" navigation task (Goldiez, Ahmad and Hancock, 2007).

The augmentation scheme was a spatially and temporally registered map that was overlaid onto a corresponding real-world maze. The experiment required the participants to cross the maze, periodically answer orientation questions, obtain a target object, and exit the maze as quickly as possible. One hundred twenty participants were evaluated in six different conditions. There were two control conditions (paper map or compass prior to entering the maze), and four experimental conditions (combinations of egocentric and exocentric maps, and continuously on or on-demand map display) (Goldiez, Ahmad and Hancock, 2007).

Performance measures involved of the duration of time to traverse the maze and percentage of maze covered. AR resulted in better performance than the control conditions in terms of accuracy by facilitating the participants' coverage of the maze. Results demonstrate that the better performance with respect to time was in the map control condition. This outcome may be due to the small size of the maze, which could be memorized. (Goldiez, Ahmad and Hancock, 2007).

According to Bimber (2012), earlier research on AR focused on head-mounted displays and backpack computers, currently it includes a variety of enabling technologies, such as camera phones and other handhelds, advanced projector-camera systems, and AR-extended professional devices, such as x-ray scanners. Therefore, AR is now a possible evolution that is used in our everyday routine.

While AR's practical applications have not yet come to the level that many people involved in the field have dreamed of, the number of these applications is gradually increasing (Bimber, 2012).

\section{Conclusion}

In conclusion, the aim of the study presented in this paper is to obtain the correlation between two types of wayfinding systems, conventional and Augmented Reality (AR) based, and the requirement of the spatial ability of the users. An investigation whether AR based wayfinding can overcome the problems facing by the conventional wayfinding are being tested to the respondents.

The results from this research showed that the evolution of AR over the course of nearly 50 years has finally made it possible to use this technology in our daily lives (Bimber, 2012). AR is expected to exhibit better performance compared to a conventional wayfinding when more complex environments are employed. These results demonstrate promising benefits in mobile AR usage in specific navigation tasks. Design guidelines were extracted to guide future AR systems continued progress in enhancing performance. However, these conclusions need to be verified in a larger and more detailed experiment.

The results of the research may encourage the development of methods for analyzing the factors that are affecting wayfinding behavior, the human individual differences, and environment factor. Therefore, more detailed research is needed to investigate the differences in conventional and AR based wayfinding by integrating with various types of variables in wayfinding and spatial ability skills in their influence on wayfinding performance. Such result could aid in the design of more legible wayfinding systems.

\section{References}

A Computational Approach for Evaluating the Facilitation of Wayfinding in Environments (2014). Retrieved from http://www.researchgate.net/profile/Ramesh_Krishnamurti2/publication/30876045_A_Computational_Approach_for_Evaluating_the_Facilitation_of_Wayfinding_i n_Environments/links/00b7d52836c1c32869000000.pdf.

Allen, G. L. (2000). Principles and practices for communicating route knowledge. Applied Cognitive Psychology 14(4), 333-359.

Allen, G. L., Miller, C. R., \& Ondracek, P. J. (1997). From knowledge to words to wayfinding: Issues in the production and comprehension of route directions. Proceedings of the International Conference on Spatial Information Theory: A Theoretical Basis for GIS 1329, 363-372.

Anastassova, M., Burkhardt, J-M., Mégard, C., \& Ehanno, P. (2005). Results from a user-centred critical incidents study for guiding future implementation of augmented reality in automotive maintenance. International Journal of Industrial Ergonomics, 35(1), 67-77.

Bimber, O. (2012). What's real about augmented reality?. Computer, 45(7), 24-25. doi:10.1109/MC.2012.247. 
Braaksma, J. P., ASCE, A. M., \& Jordan, W. C. (1980). Human orientation in transportation terminals. Transportation Engineering Journal 106(TE2), $189-202$. Carpman, J.R., \& Grant, M.A. (1993). Design that cares: Planning health facilities for patients and visitors. Chicago, III: American Hospital Pub.

Dada, E. S., \& Wirasinghe, S. C. (1999). Development of a new orientation index for airport terminals. Transportation Research Record 1662, 41-47.

Darken, R.P. (1996). Wayfinding in large-scale virtual worlds. George Washington University.

Darken, R.P., \& Peterson, B. (2001). Spatial orientation, wayfinding, and representation. Handbook of Virtual Environment Technology. Stanney, K. Ed. Retrieved from http://web.cs.wpi.edu/ gogo/courses/cs525V/papers/Darken_HVE_2002.pdf.

Denis, M., Pazzaglia, F., Cornoldi, C., \& Bertolo, L. (1999). Spatial discourse and navigation: An analysis of route directions in the city of venice. Applied Cognitive Psychology 13, 145-174.

Dünser, A., Grasset, R., \& Billinghurst, M. (2008). A survey of evaluation techniques used in augmented reality studies (Technical Report TR-2008-02). New Zealand: Human Interface Technology Laboratory.

Falk, J.H., \& Dierking, L.D. (2002). Learning from museums: Visitor experiences and the making of meaning.

Freundschuh, S. M., Gopal, S., Gould, M. D., Mark, D. M., \& Couclelis, H. (1990). Verbal directions for wayfinding: Implications for navigation and geographic information and analysis systems. Paper presented at the Proceedings, Fourth International Symposium on Spatial Data Handling, Zurich, Switzerland.

Gabbard, J. L., \& Swan, J. E. (2008). Usability engineering for Augmented Reality: Employing user-based studies to inform design. IEEE Transactions on Visualization and Computer Graphics, 14, 513-525.

Gardner, H. (1983). Frames of mind. New York: Basic Books.

Goldiez, B. F., Ahmad, A. M., \& Hancock, P. A. (2007). Effects of Augmented Reality display settings on human wayfinding performance. IEEE Transactions on Systems, Man, and Cybernetics-Part C: Applications and Reviews, 37(5). doi=10.1.1.463.6092

Levine, M., Marchon, I., \& Hanley, G. (1984). The placement and misplacement of you-are-here maps. Environment and Behavior 16(2):139-157.

Linaza, M., Marimon, D., Carrasco, P., Alvarez, R., Montesa, J., Aguilar, S. R., \& Diez, G. (2012). Evaluation of mobile Augmented Reality applications for tourism destinations. In M. Fuchs, F. Ricci, \& L. Cantoni, (Eds.), Information and communication technologies in tourism 2012. Proceedings of the International Conference in Helsingborg, Sweden (pp. 260-271). Berlin, Heidelberg: Springer- Verlag.

Lynch, K. (1960). The image of the city. Cambridge: MIT Press.

Michon, P.-E., \& Denis, M. (2001). When and why are visual landmarks used in giving directions? Spatial information theory. Foundations of Geographic Information Science : International Conference, COSIT 2001 Morro Bay, CA, USA, 2205(2001), 292-305.

Montello, D. R. (2007). The contribution of space syntax to a comprehensive theory of environmental psychology. Paper presented at the 6th International Space Syntax Symposium, Istanbul, Turkey.

O'Neill, M. J. (1991). Evaluation of a conceptual model of architectural legibility. Environment and Behavior 23(3):259-284.

Paelke, V., \& Sester, M. (2010). Augmented paper maps: Exploring the design space of a mixed reality system. ISPRS Journal of Photogrammetry and Remote Sensing, 65(3), 256-265. doi:10.1016/j.isprsjprs.2009.05.006.

Passini, R. (1984). Wayfinding in architecture. New York: Van Nostrand Reinhold Company Inc.

Passini, R. (1984). Wayfinding in architecture. Van Nostrand Reinhold Nova York; 1992. McGraw-Hill Book CO. New York, USA.

Prall, D. (2014). Wayfinding, urban design and the brain. The American City \& County. Penton Media, Inc., Penton Business Media, Inc. Retrieved from http://americancityandcounty.com/roadways/wayfinding-urban-design-and-brain.

Raubal, M., \& Worboys, M. (1999). A formal model of the process of wayfinding in built environments. Spatial information theory. Cognitive and Computational Foundations of Geographic Information Science: International Conference COSIT'99, (1661)1999, 381-400.

Seidel, A. (1982). Way-finding in public spaces: The Dallas/Fort Worth, USA Airport. 20th International Congress of Applied Psychology. Edinburgh, Scotland. 
Shanon, B. (1983). Answers to where-questions. Discourse Processes 6, 319-352.

Sorby, S. A. (1999). Developing 3D spatial visualization skills. Engineering Design Graphics Journal, 63(2), 21-32.

Sorrows, M. E., \& Hirtle, S. C. (1999). The nature of landmarks for real and electronic spaces. Spatial Information Theory. Lecture Notes in Computer Science 1661, 37-50.

Stanney, K. M., \& Salvendy, G. (1995). "Information visualization: Assisting low spatial individuals with information access tasks through the use of visual mediators,". Ergonomics, 38, 1184-1198.

Swan, J. E., \& Gabbard, J. L. (July, 2005). Survey of user-based experimentation in augmented reality. In Proceedings of 1st International Conference on Virtual 145 Reality, $\mathrm{HCl}$ International. Retrieved from http://people.cs.vt.edu/ jgabbard/publications/hcivr05.pdf.

Weisman, J. (1981). Evaluating architectural legibility: Way-finding in the built environment. Environment and Behavior 13(2):189-204.

Yovcheva, Z., Buhalis, D., \& Gatzidis, C. (2012). Overview of smartphone augmented reality applications for tourism. In ENTER 2012 Special Issue - e-Review of Tourism Research (eRTR), 10(2). Retrieved from http://ertr.tamu.edu 